\title{
FAKTOR YANG BERHUBUNGAN DENGAN PERILAKU SEKS PADA REMAJA DI DUSUN ALUR HITAM DESA SECURAI SELATAN KECAMATAN BABALAN PANGKALAN BERANDAN TAHUN 2021
}

\author{
Muthia Sari Mardha ${ }^{1}$, Endriyani Syafitri ${ }^{2}$, Sri Dewi $^{3}$ \\ Email korespondensi: muthiasarimarda@helvetia.ac.id
}

Abstrak

\begin{abstract}
Perilaku seksual remaja di Indonesia semakin memprihatinkan, data dari Survey Demografi dan Kesehatan Indonesia (SDKI) 2017 mengungkap sekitar 2\% remaja wanita usia 14-25 tahun dan $8 \%$ remaja pria direntang usia yang sama, telah melakukan hubungan seksual sebelum menikah. sebanyak $11 \%$ diantaranya mengaku mengalami kehamilan tidak diinginkan, $2 \%$ mengalami penyakit menular seksual. Tujuan penelitian ini adalah untuk mengetahui factor yang berhubungan dengan perilaku seks dikalangan remaja. Desain penelitian yang digunakan yaitu survey analitik dengan pendekatan cross sectional. Populasi dalam penelitian ini berjumlah 230 orang, dengan menggunakan rumus slovin didapat 146 responden tekhnik pengambilan sampel yaitu simple random sampling. Uji analisis data menggunakan uji chi-square. Hasil penelitian ada hubungan faktor pengetahuan agama dengan perilaku seks pada remaja dengan nilai $p$ value $0,001<0,05$, ada hubungan faktor peran orangtua dengan perilaku seks pada remaja dengan nilai $p$ value $0,003<$ 0,05 , ada hubungan factor paparan media social dengan perilaku seks pada remaja dengan nilai $p$ value $0,001<0,05$. Saran bagi orangtua untuk memberikan pengetahuan agama yang baik kepada remaja dengan rutin ke masjid atau ibadah minggu untuk yang nasrani, merubah peran orangtua menjadi teman agar para remaja mau untuk bercerita tentang segala hal dalam kehidupannya, dan memantau setiap media social yang di lakukan oleh para remaja.
\end{abstract}

Kata kunci: Perilaku Seksual, Media Sosial, Agama, Peran Orangtua

\section{Abstract}

Adolescent sexual behavior in Indonesia is increasingly concerning, data from the Indonesia Demographic and Health Survey (IDHS) 2017 reveals that around 2\% of female adolescents aged 14-25 years and 8\% of male adolescents of the same age range, have had sexual relations before marriage. as many as $11 \%$ of them admitted to having an unwanted pregnancy, $2 \%$ experienced a sexually transmitted disease. The purpose of this study was to determine the factors associated with sexual behavior among adolescents. The research design used is an analytical survey with a cross sectional approach. The population in this study amounted to 230 people, using the Slovin formula obtained 146 respondents, the sampling technique was simple random sampling. Test data analysis using chi-square test. The results showed that there was a relationship between religious knowledge and sexual behavior in adolescents with a $p$ value of $0.001<0.05$, there was a relationship between parental role factors and sexual behavior in adolescents with a $p$ value of $0.003<0.05$, there was a relationship between social media exposure factors and behavior. sex in adolescents with a $p$ value of $0.001<0.05$. Suggestions for parents to provide good religious knowledge to teenagers by regularly going to the mosque or Sunday worship for Christians, changing the role of parents into friends so that teenagers want to tell stories about everything in their lives, and monitoring every social media that teenagers do.

Keywords: Sexual Behavior, Social Media, Religion, The Role of Parents.

1,2 Dosen Prodi D3 Kebidanan Institut Kesehatan Helvetia Medan

${ }^{3}$ Mahasiswa Prodi D3 Kebidanan Institut Kesehatan Helvetia Medan

Jurnal Kebidanan-ISSN 2252-8121 


\section{Pendahuluan}

Remaja mengalami perubahan dari segi kognitif, psikososial dan fisik. Perubahan yang terjadi dari ketiga aspek tersebut akan menimbulkan problemetika yang harus dihadapi oleh remaja diantaranya yaitu problemetika yang berkaitan dengan narkoba, seksualitas, dan lain sebagainya. Kegiatan seksual merupakan remaja pada tantangan resiko terhadap sebagai masalah kesehatan reproduksi (1).

Perubahan yang terjadi pada remaja mulai aktifnya hormon seksual dalam tubuh. Hormon seks tersebut besar pengaruhnya dalam menimbulkan dorongan seksual. Hal ini menjadi titik rawan karena remaja mempunyai sifat selalu ingin tahu dan mempunyai kecenderungan untuk selalu mencoba hal-hal baru. Perkembangan arus globalisasi, kemajuan teknologi dan informasi serta bergeserannya nilai dan norma yang ada dalam masyarakat cenderung mempengaruhi pola sikap remaja untuk melakukan penyimpangan perilaku utama dalam perilaku seksualnya. Perilaku seksual adalah segala tingkah laku yang didorong oleh hasrat seksual, baik dengan lawan jenisnya maupun dengan sesama jenis. Bentuk-bentuk tingah laku ini bisa bermacam-macam,mulai dari perasaan tertarik sampai tingkah laku berkencan, bercumbu dan bersenggama. Objek seksualnya bisa berupa orang lain,orang dalam khayalan atau diri sendiri (1).

World Health Organization (WHO) yang dikutip oleh Kemkes RI, remaja adalah penduduk dalam rentang usia 10-19 tahun dengan jumlah sekiyar 1,2 miliyar atau 18\% dari jumlah penduduk dunia. WHO memperkirakan $60 \%$ remaja di dunia mengalami perilaku seksual yang tidak sehat yang sebagaian besar mengakibatkan kehamilan yang tidak diinginkan, keterlibatan remaja dalam perilaku seksual dengan pekerjaan seks komersial (PSK) juga sangat beresiko tinggi mengalami penyakit seksual, terutama ikut adil dalam penularan HIV/AIDS terhadap 60\% remaja (2).

Perilaku seksual remaja di Indonesia semakin memprihatinkan, data dari Survey Demografi dan Kesehatan Indonesia (SDKI) 2017 mengungkap sekitar 2\% remaja wanita usia 14-25 tahun dan 8\% remaja pria direntang usia yang sama, telah melakukan hubungan seksual sebelum menikah. sebanyak $11 \%$ diantaranya mengaku mengalami kehamilan tidak diinginkan, 2\% mengalami penyakit menular seksual (3). Dari hasil survei yang dilakukan oleh komite Perlindungan Anak Indonesia (KPAI) tahun 2016 yang dikutip oleh Nurmaguphita menyatakan sebanyak 32\% remaja usia 14-18 tahun di kota-kota besar di Indonesia (Jakarta, Surabaya, Bandung, dan Yogyakarta) pernah berhubungan seks. Hasil survei lain juga menyatakan satu dari empat remaja di Indonesia melakukan hubungan seksual pranikah dan membuktikan $62,7 \%$ remaja kehilangan keperawanan saat masih duduk di bangku SMA, bahkan diantaranya pernah berbuat extream yaitu melakukan aborsi (4). 
Dampak perilaku seks remaja usia sekolah berpengaruh terhadap perilaku sosial, yakni banyak pribadi yang mengalami gangguan jiwani dan muncul konflik budaya yang ditandai dengan keresahan sosial serta ketidak rukunan kelompok-kelompok sosial. Sebagai akibat lebih lanjut timbul ketidak seimbangan , disharmoni, ketegangan kecemasan, ketakutan dan kerusuhan sosial. Dalam pandangan masyarakat,remaja putri yang hamil merupakan aib keluarga yang melanggar norma-norma terhadap sosial dan agama. Peenghakiman sosial ini tidak jarang meresap dan terus tersosialisasi dalam dirinya. Perasaan bingung, cemas, malu, dan bersalah dialam pelajar setelah mengetahui kehamilan bercampur dengan depresi, pesinis terhadap masa depan yang kadang disertai dengan rasa benci dan marah baik pada diri sendiri maupun kepada pasangan, dan kepada nasib yang membuat kondisi sehat secara fisik, sosial, dan mental yang berhubungan dengan sistem, fungsi dan proses reproduksi anak muda tidak terpenuhi (5).

Perilaku seks bebas pada remaja dapat terjadi karena adanya faktor yang mendorong terjadinya perilaku antara lain pengetahuan, sifat, kepercayaan dan nilainilai akibat penumpukan perilaku interaksi keseharian remaja dengan keluarga. Faktor pemungkin juga sangat besar pengaruhnya dimana adanya fasilitas yang tersedia antara lain penggunaan HP android (smartphone) yang telah meramba dikalangan remaja dan warung internet (warnet) yang mudah didapat dengan biaya yang relatif terjangkau.
Pergaulan dengan teman sebaya dan dukungan orang tua menjadi faktor pendorong terjadinya perilaku seksual remaja. Oleh karena itu, orang tua wajib untuk selalu berkomunikasi dan memperhatikan perkembangan anaknya. Sulitnya remaja untuk berkomunikasi khususnya dengan orang tua, pada akhirnya akan menyebabkan perilaku seksual yang tidak diharapkan (6).

Faktor yang mempengaruhi perilaku seks remaja adalalah orangtua. Dimana orangtua dapat mempengaruhi perilaku seksual anak melalui tiga cara yaitu komunikasi, bertindak sebagai contoh (role model) dan pengawasan. Orang tua seharusnya pertama kali memberikan pengetahuan perilaku seksual kepada anaknya. Banyak orang tua yang masih mentabukan pembicaraan mengenai seksual dengan anaknya, orang tua tidak terbuka pada anak sehinga anak cenderung tidak mendapatkan pendidikan perilaku seksual sejak dini. Hal ini akan membuat jarak antara anak dengan orang tua sehinga pengetahuan seksualitas anak sangatlah kurang.

Penelitian Anggita F. R (2018) yang berjudul "Perilaku Seksual Remaja Ditinjau dari Religius dan Pola Asuh Permisif Pada SMA X Rowosari Kendal”. Hasil analisis komunikasi intepersonal orag tua setelah dikontrol variabel temen sebaya, media masa dan relijiusitas berpengaruh sebesar $49 \%$. Kesimpulan dari penelitian ini adalah perilaku seksual pranikah remaja beresiko terjadi pada remaja karena kominikasi 
interpersonal orang tua yang tidak baik. Faktor lain yang mempengaruhi perilaku seksual pranika beresiko pada remaja adalah tingkat religiusitas, dan paparan media pornografi (7). Tujuan Penelitian ini adalah untuk mengetahui faktor-faktor yang memengaruhi perilaku seks pada remaja.di Dusun Alur Hitam Desa Securai Selatan Kecamatan Babalan Pangkalan Berandan Tahun 2021.

\section{Metode}

Desain penelitian ini menggunakan survei analitik yaitu dengan pendekatan cross sectional, yang dimana variabel sebab atau resiko dan akibat atau kasus yang terjadi pada obyek penelitian diukur dan dikumpulkan secara simultan, sesaat atau satu kali saja dalam satu kali waktu (dalam waktu yang bersamaan) (8). Penelitian ini dilakukan di Dusun Alur Hitam, Desa
Securai Selatan, Kecamatan Babalan, Pangkalan Brandan. Populasi dalam penelitian ini adalah remaja yang berada di Dusun Alur Hitam, Desa Securi Selatan, Kecamatan Babalan, Pangkalan Berandan sebanyak 230 orang. Teknik pengambilan sampel yaitu dengan menggunakan rumus dari Slovin dengan jumlah sampel yang akan diteliti sebanyak 146 orang dari jumlah populasi penelitian. Sampel yang digunakan dalam penelitian ini menggunakan teknik Simple Random Sampling. Tekhnil Pengumpulan data menggunakan kuesioner pengetahuan agama sebanyak 20 soal, peran orangtua sebanyak 10 pernyataan, paparan media sosial sebanyak 5 pernytaan, dan perilaku seks sebanyak 10 pernytaan. Uji analisis data yaitu analisis bivariat dengan menggunakan uji Chi-Square.

\section{Hasil dan Pembahasan}

Tabel 1. Karakteristik Responden

\begin{tabular}{lcc}
\hline \multicolumn{1}{c}{ Karakteristik } & $\mathrm{N}$ & $\%$ \\
\hline 1. Pendidikan & 8 & 5,5 \\
a. SMP & 136 & 93,2 \\
b. SMA & 2 & 1,4 \\
c. Perguruan Tinggi & & \\
2. Jenis Kelamin & 89 & 61 \\
a. Laki-laki & 57 & 39 \\
b. Perempuan & & \\
3. Pengetahuan & 98 & 67,2 \\
a. Kurang & 46 & 31,5 \\
b. Cukup & 2 & 1,3 \\
c. Baik & 112 & 76,7 \\
4. Peran orangtua & 34 & 23,3 \\
a. Tidak Berperan & & \\
b. Berperan & 107 & 73,3 \\
5. Paparan Media Sosial & 39 & 26,7 \\
a. Terpapar & & 74,7 \\
b. Tidak Terpapar & 109 & 25,3 \\
6. Perilaku Seksual & 37 & \\
a. Berat & & \\
b. Ringan & & \\
\hline
\end{tabular}


.Tabel 2 Hubungan Variabel Bebas dan Variabel Terikat

\section{Perilaku Seks}

\begin{tabular}{lcccccc}
\hline \multirow{2}{*}{ Karakteristik Responden } & \multicolumn{2}{c}{ Berat } & \multicolumn{2}{c}{ Ringan } & $\boldsymbol{\alpha}$ & P Value \\
\cline { 2 - 7 } & $\mathbf{N}$ & $\mathbf{\%}$ & $\mathbf{N}$ & $\mathbf{\%}$ & \\
\hline 1. Pengetahuan Agama & 79 & 54,1 & 19 & 13,0 & 0,001 \\
$\quad$ a. Kurang & 30 & 20,5 & 16 & 11 & & \\
$\quad$ b. Cukup & - & - & 2 & 1,4 & & \\
$\quad$ c. Baik & & & & & 0,05 & \\
2. Peran orangtua & 106 & 72,7 & 6 & 4,1 & & 0,003 \\
a. Tidak Berperan & 3 & 2 & 31 & 21,2 & & \\
b. Berperam & & & & & & 0,001 \\
3. Paparan Media Sosial & 105 & 71,9 & 2 & 1,4 & & \\
a. Terpapar & 4 & 2,8 & 35 & 24 & & \\
b. Tidak Terpapar & & & & & & \\
\hline
\end{tabular}

Faktor Pengetahuan Agama dengan

\section{Perilaku Seks pada Remaja}

Hasil penelitian didapatkan p-value sebesar $0,001<0,05$ artinya terdapat hubungan signifikan antara pengetahuan agama dengan perilaku seks pada remaja di Dusun Alur Hitam, Desa Securai Selatan, Kecamatan Babalan, Pangkalan Berandan.

Hal ini sejalan dengan Penelitian Anggita F. R (2018) yang berjudul "Perilaku Seksual Remaja Ditinjau dari Religius dan Pola Asuh Permisif Pada SMA X Rowosari Kendal". Teknik pengambilan sampel dalam penelitian ini cluster random sampling. Didapatkan hasil penelitian adalah korelasi antara religiusitas dan pola asuh permisif dengan perilaku seksual pada remaja (Ry $(1,2)$ $=0,339, \mathrm{p}<0,05)$, ada hubungan negatif antara religiusitas dan perilaku seksual pada remaja $(\mathrm{r} 1 \mathrm{y}=-0,326, \mathrm{p}<0,05)$, ada korelasi positif antara pola asuh permisif dan perilaku seksual pada remaja, $(\mathrm{r} 1 \mathrm{y}=0,258, \mathrm{p}<0,05)(7)$.
Penelitian ini sesuai dengan teori bahwa agama berperan sangat penting dalam proses kehidupan manusia. Kehidupan beragama yang baik dan benar ditandai dengan pengertian, pemahaman dan ketaatan dalam menjalankan ajaran-ajaran agama dengan baik tanpa dipengaruhi oleh situasi kondisi apapun. Dalam keadaan apa saja, orang yang taat beragama selalu dapat menetapkan diri dan mengendalikan diri agar tidak berbuat hal-hal yang bertentangan dengan ajaran agama (7).

\section{Faktor Pengetahuan Peran Orangtua dengan perilaku seks pada Remaja}

Hasil penelitian menggunakan Chisquare diperoleh $p$-value sebesar $0,003<0,05$ artinya terdapat hubungan signifikan antara peran orangtua dengan perilaku seks pada remaja di Dusun Alur Hitam, Desa Securai Selatan, Kecamatan Babalan, Pangkalan Berandan.

Hal ini sejalan dengan penelitian Andriani (2016) yang berjudul "Hubungan 
Pengetahuan Dengan Perilaku Seksual Remaja

Di SMK N 1 Kendari Kota Kendari Tahun 2016". Hasil penelitian menunjukkan ada hubungan akses media informasi dengan perilaku seksual remaja di SMK N 1 Kendari Kota Kendari Tahun 2016 dengan keeratan hubungan sedang (Phi $\varnothing=0,496$ ). Dan ada hubungan peran keluaraga dengan perilaku seksual remaja di SMK N 1 Kendari Kota Kendari tahun 2016 dengan keeratan hubungan sedan $(\mathrm{PhI} \varnothing=0,328)(9)$.

Penelitian ini sesuai dengan teori bahwa proses pembentukan atau perubahan perilaku dapat dipengaruhi oleh beberapa faktor baik dari dalam maupun dari luar individu. Aspek-aspek dalam diri individu yang sangat berperan/berpengaruh dalam perubahan perilaku adalah persepsi, motivasi dan emosi (10). Orang tua dapat mempengaruhi perilaku seksual anak melalui tiga cara yaitu komunikasi,bertindak sebagai contoh ( role model) dan pengawasan. Orang tua seharusnya yang pertama kali memberikan pengetahuan perilaku seksual kepada anaknya. Banyak orang tua yang masih mentabukan pembicaraan mengenai seksual dengan anaknya, orang tua tidak terbuka pada anak sehingga anak cenderung tidak mendapatkan pendidikan perilaku seksual sejak dini (13).

\section{Faktor Paparan Media Sosial dengan Perilaku Seks Pada Remaja}

Hasil penelitian menggunakan Chisquare diperoleh $p$-value sebesar $0,001<0,05$ artinya terdapat hubungan signifikan antara paparan media sosial dengan perilaku seks pada remaja di Dusun Alur Hitam, Desa
Securai Selatan, Kecamatan Babalan, Pangkalan Berandan.

Hal ini sejalan dengan Penelitian Erna Dusra (2017) yang berjudul "Pengaruh Media Internet Terhadap Perilaku Menyimpang Remaja Di Sekolah Menengah Atas Negeri 1 Maros". Teknik analisis yang digunakan dalam penelitian ini adalah analisis normative dan analisis Chi-Square. Hasil penelitian menunjukkan bahwa terdapat pengaruh yang signifikan antara menonton film/video porno di media internet dengan perilaku menyimpang (seksual) di SMA Negeri 1 Maros. diperoleh nilai $\mathrm{p}=0,000(<0,01)$, menonton pornografi di internet memberikan sumbangan efektif terhadap perilaku menyimpang (seksual) (11)

Penelitian ini juga sejalan dengan teori bahwa media sosial merupakan pengembangan dari internet yang memungkinkan penggunanya untuk berbagi serta berdiskusi mengenai kehidupan manusia di jaman sekarang. Media sosial merupakan tahap perubahan dimana seseorang membaca serta membagikan berita, konten serta informasi terhadap orang lain. Media sosial adalah perpaduan antara teknologi dengan sosiologi yang mengubah monolog (one to many) menjadi dialog (many to many) serta mengubah seseorang dari pembaca konten menjadi pencipta konten. Ada banyak yang dapat dilakukan di sosial media seperti menbagikan konten, opini, pandangan serta keinginan untuk berinteraksi ke dalam sebuah komunitas yang dapat dibangun di dalam sosial media (6). 


\section{Kesimpulan}

Ada Hubungan pengetahuan agama, peran orangtua, dan paparan media sosial dengan perilaku seks pada remaja. Untuk itu diharapkan bagi orangtua untuk memberikan pengetahuan agama yang baik kepada remaja dengan rutin ke masjid atau

\section{Daftar Pustaka}

1. Harianti Rini; Mianna. Pendidikan Seks Usia Dini Teori dan Aplikasi. Yogyakarta: Transmedia; 2016.

2. Kemenkes. Menkes : Remaja Indonesia Harus Sehat.

htttps://www.kemenkes.go.id. 2018;

3. Pusdatin Kemenkes. Infodatin Reproduksi.

http://pusdatin.kemenkes.go.id. 2017;

4. Nurmaguphita. Komisi Perlndungan Anak (KPAI). https://www.kpai.go.id. 2016;

5. Welina Sebayang; Destya Yohana Gultom; Eva Royani Sidabutar. Perilaku Seksual Remaja. Yogyakarta: CV. Budi Utama; 2018.

6. Fransisca Vina Oktavia. Hubungan Antara Penggunaan Media Sosial Dengan Perilaku Seksual Remaja. Universitas Katolik Soeguapranata ibadah minggu untuk yang nasrani, merubah peran orangtua menjadi teman agar para remaja mau untuk bercerita tentang segala hal dalam kehidupannya, dan memantau setiap media social yang di lakukan oleh para remaja.

Semarang; 2017.

7. Anggita Fani Rosalina. Perilaku Seksual Remaja Ditinjau dari Religius dan Pola Asuh Permisif Pada SMA X Rowosari Kendal. UNISSULA; 2018.

8. Cecep Dani Sucipto. Metodologi Penelitian Kesehatan. Yogyakarta: Gosyen Publishing; 2020.

9. Harni Andriani. Hubungan Pengetahuan Dengan Perilaku Seksual Remaja Di SMK N 1 Kendari Kota Kendari Tahun 2016. https://ojs.uho.ac.id. 2016;

10. Yayi Suryo Prabandri; Retna Siswi; dkk. Ilmu Sosial Perilaku Untuk Kesehatan Masyarakat. Yogyakarta: Gajah Mada University Press; 2020.

11. Erna Dusra. Pengaruh Media Internet Terhadap Perilaku Menyimpang Remaja Di Sekolah Menengah Atas Negeri 1 Maros. UIN Alauddin Makassar; 2017. 